\title{
Corrigendum
}

\section{Corrigendum to "Theoretical Model for the Performance of Liquid Ring Pump Based on the Actual Operating Cycle"}

\author{
Si Huang $(\mathbb{D}$, Jing He $\mathbb{D}$, Xueqian Wang, and Guangqi Qiu \\ School of Mechanical and Automotive Engineering, South China University of Technology, Guangzhou 510640, China \\ Correspondence should be addressed to Si Huang; huangsi@scut.edu.cn \\ Received 17 December 2017; Accepted 21 December 2017; Published 8 January 2018 \\ Copyright (C) 2018 Si Huang et al. This is an open access article distributed under the Creative Commons Attribution License, which \\ permits unrestricted use, distribution, and reproduction in any medium, provided the original work is properly cited.
}

In the article titled "Theoretical Model for the Performance of Liquid Ring Pump Based on the Actual Operating Cycle" [1], there was an error in Equation (5). The corrected equation is shown below.

The compression ratio $\sigma$ of the pressure at the circumferential angle $\varphi$ to the suction pressure needs to solve an algebraic equation:

$$
\frac{1}{\sigma^{2}}=A^{2}\left(1-\frac{\sigma-1}{\varepsilon}\right)
$$

where $A=2(R-\rho) / \mu r_{2}\left[(1-\alpha)^{2}-v^{2}\right] ; \varepsilon=\rho_{l} \omega^{2} r_{2}^{2} / 2 p_{s}$.

\section{References}

[1] S. Huang, J. He, X. Wang, and G. Qiu, "Theoretical Model for the Performance of Liquid Ring Pump Based on the Actual Operating Cycle," International Journal of Rotating Machinery, vol. 2017, Article ID 3617321, 9 pages, 2017. 


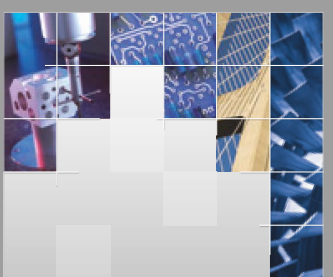

\section{Enfincering}
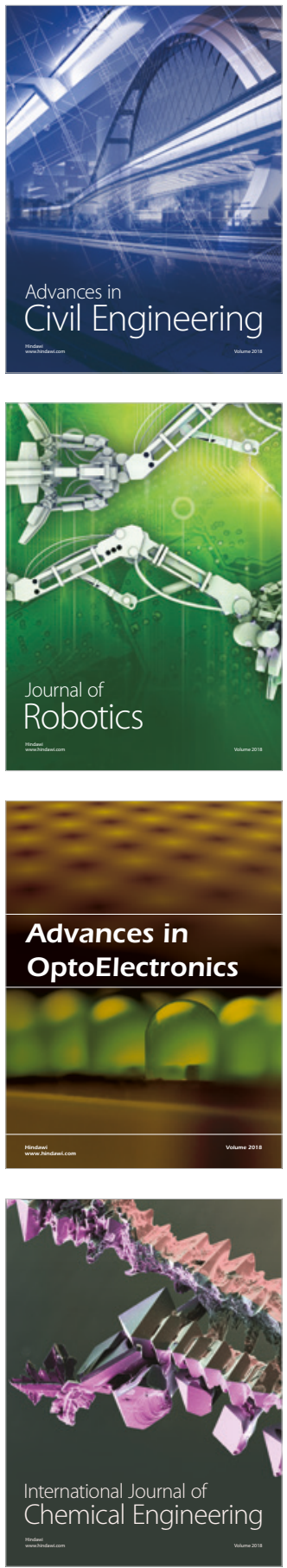

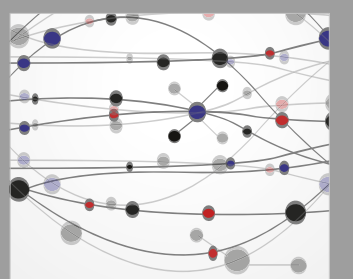

\section{Rotating \\ Machinery}

The Scientific World Journal

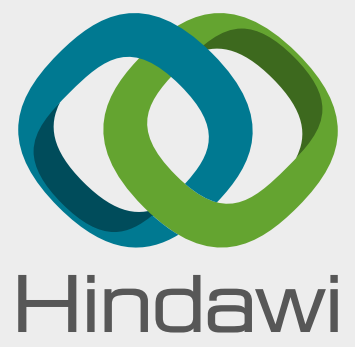

Submit your manuscripts at

www.hindawi.com
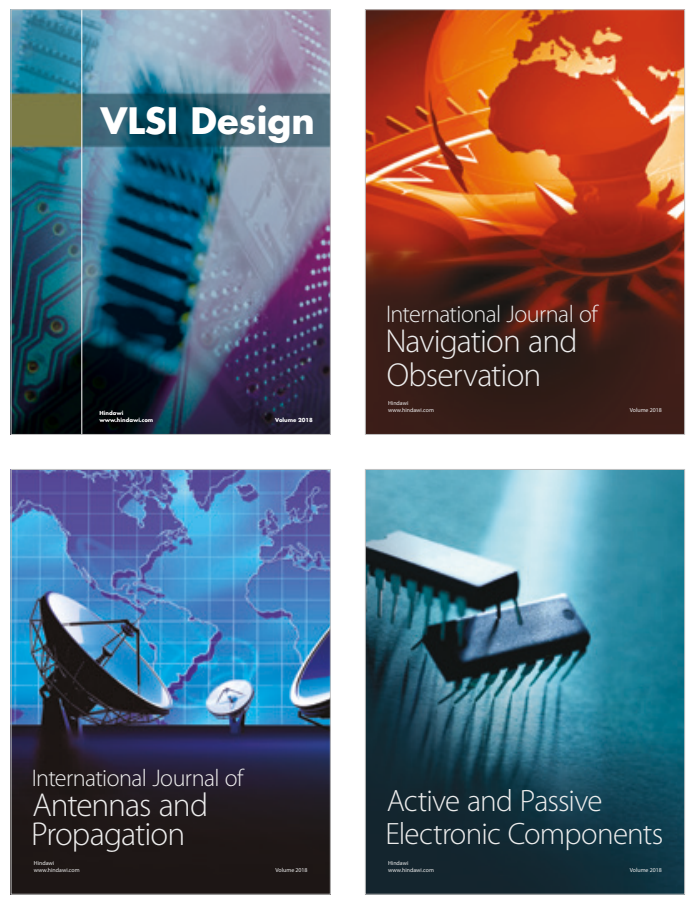
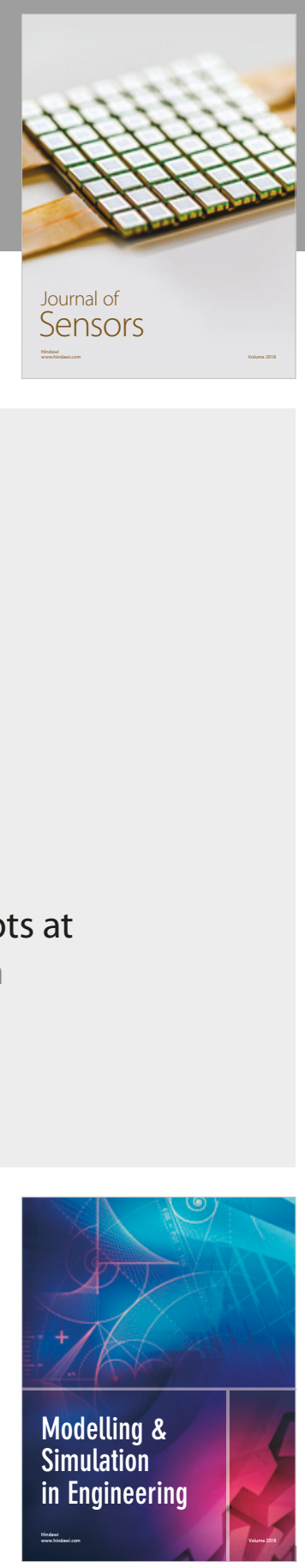

\section{Advances \\ Multimedia}
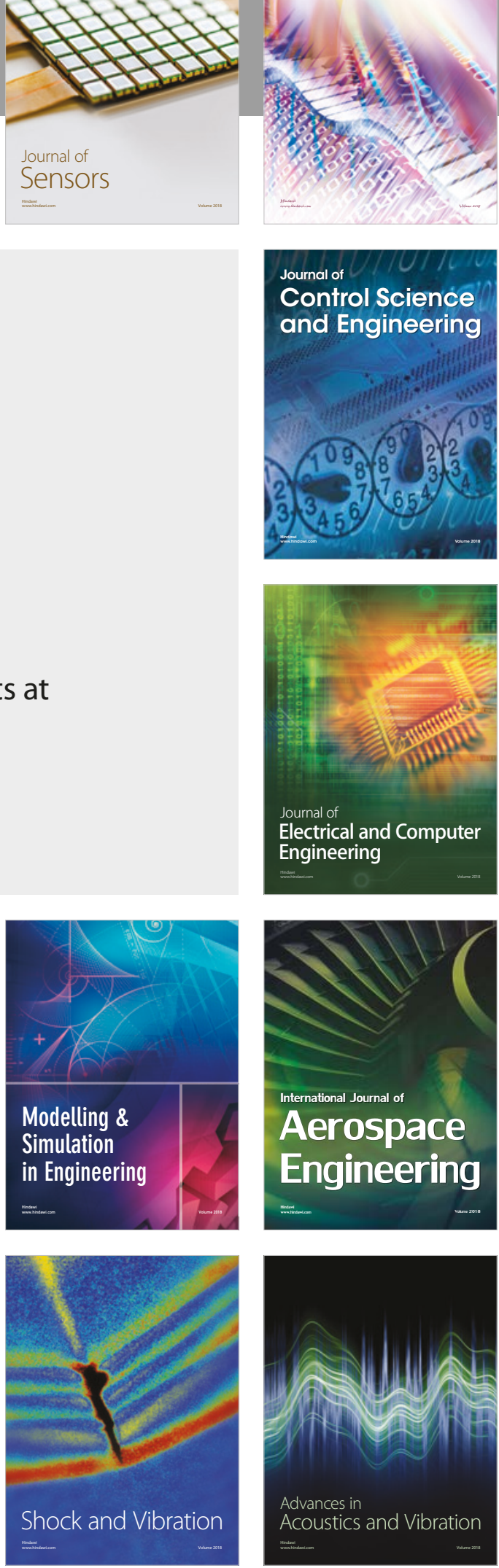